\title{
Proposing a life cycle land use impact calculation methodology
}

\author{
W.M.J. Achten ${ }^{1}$, E. Mathijs ${ }^{2}$, B. Muys ${ }^{1}$ \\ ${ }^{1}$ Katholieke Universiteit Leuven, Division Forest, Nature and Landscape, Celestijnenlaan 200 E Box \\ 2411, BE-3001 Leuven, Belgium, wouter.achten@ees.kuleuven.be \\ ${ }^{2}$ Katholieke Universiteit Leuven, Division Agricultural and Food Economics, Willem de Croylaan 42 \\ Box 2424, BE- 3001 Leuven, Belgium
}

Keywords: biodiesel, exergy, LCA, Land use impact assessment

\begin{abstract}
The Life Cycle Assessment (LCA) community is yet to come to a consensus on a methodology to incorporate land use in LCA, still struggling with what exactly should be assessed and which indicators should be used. To solve this problem we start from concepts and models describing how ecosystems function and sustain, in order to understand how land use affects them. Earlier our research group presented a methodology based on the ecosystem exergy concept. This concept as based on the hypothesis that ecosystems develop towards more effective degradation of exergy fluxes passing through the system and is derived from two axioms: the principles of $(i)$ maximum exergy storage and the (ii) maximum exergy dissipation. This concept aiming at the area of protection natural environment is different from conventional exergy analysis in LCA focusing on natural resources. To prevent confusion, the ecosystem exergy concept is further referred to as the MAximum Storage and Dissipation concept (MASD concept). In this paper we present how this concept identifies end-point impacts, mid-point impacts and mid-point indicators. The identified end-point impacts to assess are Ecosystem Structural Quality (ESQ) and Ecosystem Functional Quality (EFQ). In order to quantify these end-point impacts a dynamic multi-indicator set is proposed for quantifying the mid-point impacts on soil fertility, biodiversity and biomass production (quantifying the ESQ) and soil structure, vegetation structure and on-site water balance (quantifying the EFQ). Further we present an impact calculation method suitable for different environmental assessment tools and demonstrate the incorporation of the methodology in LCA.
\end{abstract}

\section{Introduction}

Human activities have spatial needs for extraction of resources, forestry and agriculture, infrastructure and dwellings, industrial production processes and landfill. The use of land will often make the land unavailable for other uses, but may also change the quality of the land in terms of life support or potentiality for other land use. In an LCA context land use was therefore defined as intensive human activities, aiming at exclusive use of land for certain purposes and adapting the properties of land areas in view of these purposes.

Land use and land use change are considered by the international community as a significant aspect of global change, which may induce climate change, desertification and loss of biodiversity and life support functions .

Several methods have been developed for the assessment of environmental impacts generated by land use and land use change (e.g. monitoring procedures, standards with principles, criteria and indicators 
(PC\&I), environmental impact assessment (EIA) and life cycle assessment (LCA) (Baelemans \& Muys 1998)). These methods and tools still face specific and shared problems regarding the land use impact assessment. Among these problems the selection and definition of relevant and measurable indicators seems one of the most persistent (Baelemans \& Muys 1998). Discussions on land use impact in LCA community seem to reveal a lack of consensus on what exactly has to be assessed . According to the authors the reason for these problems lies in the lack of a solid theoretical concept which can serve as paradigm in which land use and land use change impacts can be evaluated and assessed.

In this paper we propose a method to assess land use impact on the natural environment and life support functions (areas of protection). We propose to do this assessment from an ecosystem perspective, using a theoretical concept describing how ecosystems are structured and how they function. The rationale behind this starting point is, that we can only know how we damage an ecosystem by human induced land use if we understand how it works, lives and sustains. Based on the insight of this concept, we identify what exactly has to be assessed, translated in land use end-point impacts which should be assessed (also see ). Based on published land use cause effect chains we propose a universally applicable (mid-point) indicator set. Since the links between the mid-point impacts and the end-point impacts are based on the theoretical concept the mid-point indicators are also compatible with the theoretical concept.

\section{Background}

Ecosystem theories can be divided in three groups: (i) succession models, (ii) resistance models and (iii) energy models. These latter combine the baseline of the succession models, which put most emphasis on internal control of the ecosystem, and the baseline of the resistance models, which put most emphasis on external control of the ecosystem. Energy models recognize the internal control of the self-organized complex system as a source of stability, but also considers the dependence of the ecosystem from external energy sources, which makes ecosystems stable only if they can sustain the bio-energetic control in case of external disturbances.

Among the energy models, the ecosystem exergy concept was introduced by Schneider \& Kay (1994). According to them, ecosystems are open systems subject to continuous energy influxes. They tend to increase their internal exergy level, in order to evolve as far as possible from thermodynamic equilibrium. Doing so they develop towards more effective degradation of energy fluxes passing through the system. The concept is derived from two axioms: the principles of (i) maximum exergy storage and the (ii) maximum exergy dissipation. According to the maximum exergy storage principle an ecosystem on any site, with given abiotic features and local gene pool, would develop towards a state of highest possible exergy storage in terms of biomass, genetic information and complex structural networks (Jorgensen \& Mejer 1979; Bendoricchio \& Jorgensen 1997). The principal of maximum dissipation means that for any site an ecosystem would tend towards maximum dissipation of the exergy influxes in form of radiation, water, nutrients, air and genetics .The content of this ecosystem exergy concept is promising for further advances in land use impact. For a review on the ecosystem exergy concept see .

It is important to stress that this concept, which aims at evaluating the area of protection of the natural ecosystem is different from conventional exergy analysis in LCA, which aims at accounting the use of natural resources. More on this topic can be found in . In this paper we use the ecosystem exergy 
concept to justify the identification of the end-point, mid-point impacts and the indicator set used for quantification. To prevent from confusion with conventional exergy analysis, the authors will further refer to it as MAximum Storage and Dissipation concept (MASD concept), which stands for the succession and evolutionary trends observed in ecosystems (in modelling terms called goal functions), namely: (i) maximization of exergy storage in biomass, genetic information and structural networks (= maximization of Ecosystem Structural Quality, ESQ) and (ii) maximization of exergy dissipation from radiative, material and genetic influxes (= maximization of Ecosystem Functional Quality, EFQ, i.e. the buffering capacity which sustains the control of the ecosystem over the fluxes passing through it and its stability despite disturbances). These goal functions are interdependent of each other. Higher ESQ will lead to higher EFQ, which in turn will lead to further increase of the ESQ.

\section{Approach}

\section{What should be assessed?}

There is no agreement so far in the LCA community on what exactly should be assessed in the land use impact assessment. Based on the ecosystem concept explained above and the definition of land use we identify the end-point impacts which should at least be assessed.

In the light of the MASD concept the land use definition of Lindeijer et al. indicates that land use refers to human interventions bringing and keeping land at a certain Ecosystem Structural Quality (ESQ). In the MASD concept the affected ESQ will influence the Ecosystem Functional Quality (EFQ). Both goal functions are fundamental. Therefore we propose to assess the impacts on these two functions as being end-point impact of human land use interventions:

1. Impact on the Ecosystem Structural Quality (ESQ) (how does the human land use intervention influence the amount of living and dead biomass, the species composition and the complex ecosystem network structure?)

2. Impact on the Ecosystem Functional Quality (EFQ) (how does the human land use interventions influence the capacity of the land to keep control over solar energy, water, sediment and nutrients, to maintain and restore ESQ, and to buffer future disturbances?)

\section{How to quantify the ESQ and EFQ indicators?}

In order to quantify the ESQ and EFQ, relevant mid-point impacts of land use related interventions are selected, based on earlier published cause-effect chains (the selection is given in Figure 1). The list of mid-point impacts is non-exhaustive but, according to us, necessary to be assessed. Notice that we restrict ourselves to the land use interventions as human activities.

In a further step, the mid-point impacts have to be categorized to the end-point impacts (arrows in figure 1) and mid-point indicators have to be identified to quantify the mid-point impacts. This is an iterative process, since the content of the possible indicators determines the link between the midpoint and end-point (e.g. based on the explanation of the MASD concept, it might be expected that 'vegetation structure' should be categorized as ESQ, but the most suitable indicators quantifying the 'vegetation structure', namely leaf area index and vertical space distribution actually say more about the dissipation than about storage, see further). Furthermore, we aim (i) at proposing a simple impact score calculation method which is the same for each indicator (see further), (ii) at using easily available and/or measurable indicators and (iii) at selecting mid-point indicators representing four 
basic impact themes: soil, biodiversity, vegetation and water and that all themes contain indicators linked both to ESQ and EFQ.

\section{Reference system land use change and land use occupation}

The indicator values will give us a valuation of the ESQ and EFQ under a certain land use. An impact on ESQ and EFQ, caused by human induced land use change (LUCh), has to be measured against a reference system. The new installed land use ('Project LU'), should only be burdened for the change it makes compared to the land use it directly pushed away or will directly push away ('Former LU'), which, as such, should be the reference system (Figure 2). For land use occupation (LUOcc) impact, the potential natural vegetation (PNV) is taken as reference. Since ESQ and EFQ are site specific, we propose to calculate the burdens (e.g. $\mathrm{ESQ}_{\text {Reference }}-\mathrm{ESQ}_{\text {ProjectLU }}$ ) relative (\%) to the maximum potential ESQ and EFQ (or the PNV) of that specific location (Figure 2). This reasoning will lead us further to an impact indicator calculation method (see further).

Following Lindeijer (Lindeijer 2000) the impact caused by land use change and by land use occupation is separated, because land use change can improve the land quality, compared with the situation before the change, but the land use occupation has still impacts on the maximization of storage and dissipation compared to absence of human induced land use. However, the land use occupation is seen as a quality difference between the maximal possible ESQ and EFQ (PNV) and the project ESQ and EBC.

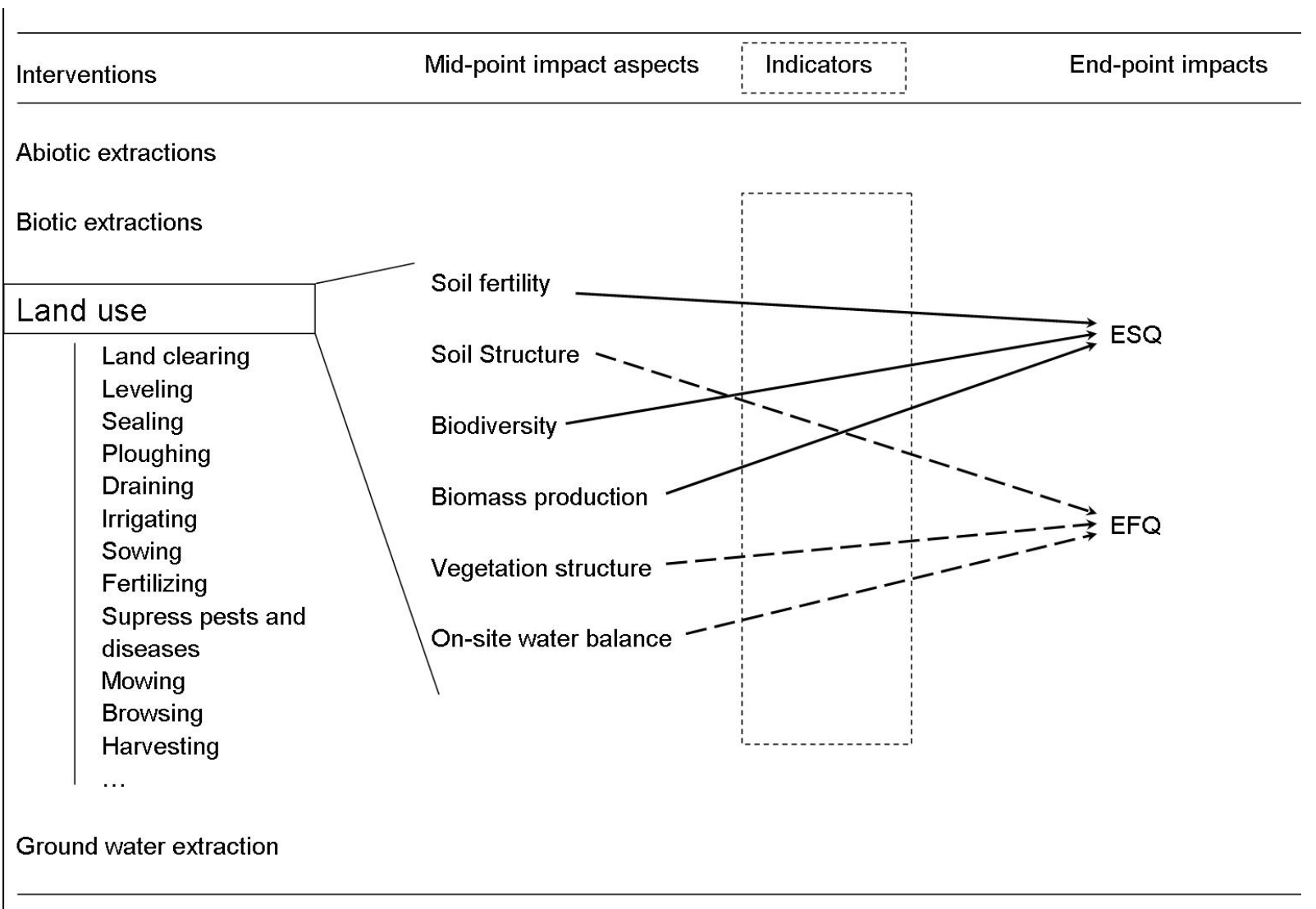

Figure 1. Non-exhaustive overview of mid-point impacts of land use interventions. The arrows show the linkage of mid-point impacts with the end-point impacts. 


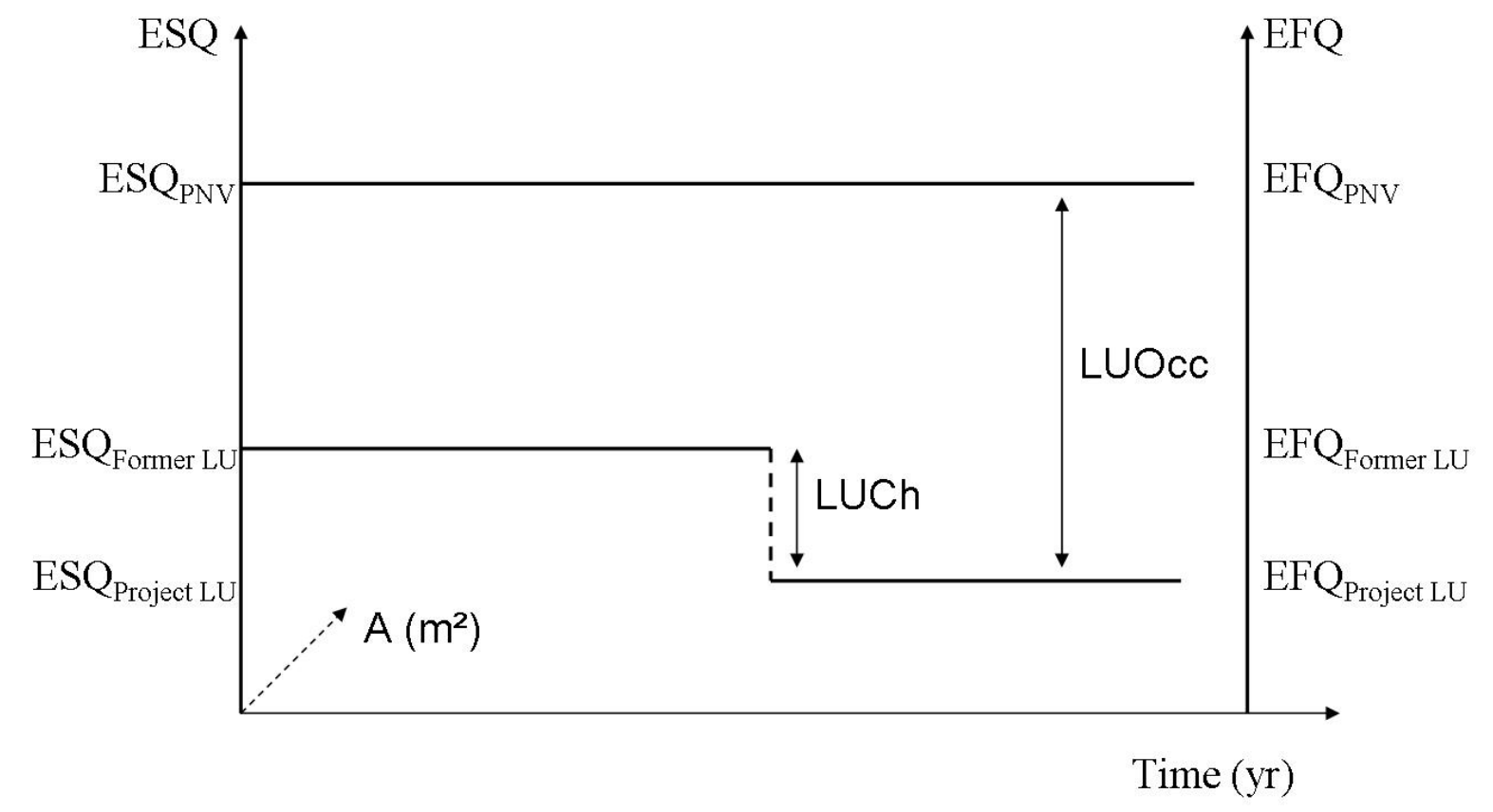

Figure 2. Simplified depiction of land quality of the new induced land use (Project LU), former land use (Former LU) and potential natural vegetation (PNV).

\section{Incorporation in LCA}

The indicator set and the calculation method will give an environmental impact. From a LCA point of view these impacts should be reported per functional unit (FU) in order to be able to compare scenarios and managements around the world. Therefore we present a general formula for land use impact (S) calculation. This formula has two components: impact indicator component (I) and a LCA component (F) (Eq. 1).

$\mathrm{S}=\mathrm{I} \times \mathrm{F}$

Eq. 1

\section{Results}

\section{Impact indicator component}

\section{Set of mid point indicators}

In this section a set of indicators is proposed. This set can be considered flexible. For each mid-point impact aspect two indicators are proposed, except for biodiversity. According to specific situations, specific aims of the user, data availability, measurement feasibility, etc. the users can choose to use both or just one. Further, there is still scope for extra possible indicators per mid-point aspect, according to users' expertise.

Indicators quantifying ESQ

Soil fertility

For assessing impact on soil fertility two indicators are proposed: (i) cation exchange capacity (CEC) and (ii) base saturation (BS) of the topsoil $(0-30 \mathrm{~cm})$. CEC has a direct impact on the soil ability to support vegetation and therefore on the ability of the ecosystem to produce and store biomass . Loss of 
BS is considered an impact because it decreases the ecosystem productive capacity and therefore its capacity to store biomass and genetic information. Both CEC and BS are directly affected negatively or positively by management practices . Both CEC and BS require on-field measurements with standard chemical analysis of soil samples.

Biomass production

Any decrease of biomass due to harvest in any of its forms or by changes in site quality is assumed to cause a decrease of ecosystem control over energy (e.g. radiation), nutrients and water flows . Therefore the proposed indicators look at the (i) total above biomass (TAB) and (ii) free net primary production (fNPP). Net primary production (NPP) is controlled by physical, environmental and biotic factors (Garcia-Quinjano \& Barros 2005). fNPP is the part of NPP which is not harvested but stays in the ecosystem to fulfil life support functions (Lindeijer 2000). fNPP data is available on a world-wide scale (Lindeijer 2000), TAB is best measured on the field.

Species diversity

Based on the same reasoning of data availability as Lindeijer (Lindeijer 2000) we opted for vascular plant species number as sole biodiversity indicator. This indicator required on-field measurements.

\section{Indicators quantifying $E F Q$}

Soil structure

Impacts on soil structure can be assessed by: (i) soil organic matter (SOM) of the topsoil $(0-30 \mathrm{~cm})$ and (ii) soil compaction. SOM is an good indicator of the dynamic nature of soils and for the physical and chemical filter and buffer capacity (Milà i Canals 2003). Soil compaction reduces the volume of air in the soil and reduce infiltration rate and as such can have negative impacts on root development and biomass production and increased surface runoff . In Fig. 1 the soil structure impact aspect is characterized as impact on EBC, Therefore infiltration rate is used as soil compaction indicator (I) (see further). This indicator will highlight changes in the capacity of the ecosystem to buffer water and sediment flows. SOM is easily available while I is best measured in the field.

Vegetation structure

Characterized to EBC, the proposed indicators are (i) leaf area index (LAI) and (ii) vertical space distribution. LAI is a reliable indicator of a systems absorption capacity of solar radiation, systems reduction potential of kinetic energy from raindrops and systems interception and retention of rainwater . Vertical space distribution, calculated by dividing the canopy height of the dominant stratum of the land use $(\mathrm{H})$ by the number of vertical strata in the land use (S), gives an idea about the vertical structure of the vegetation interface buffering solar radiation, rainfall, wind, among others flows. For the same height of the dominant layer in the vertical structure, a lower number of layers would decrease the optimal or maximum buffer capacity of the ecosystem . A LAI global $1 \mathrm{~km}$ geodataset is available at the Land Processes Distributed Active Archive Centre (LP DAAC, USA) (https://lpdaac.usgs.gov/), but can also be measured in the field by hemispheric photography. Vertical space distribution is best measured in the field.

On-site water balance

Here evapotranspiration and soil cover are proposed. Loss of evapotranspiration level indicates a decrease of health and productivity of the ecosystem and a loss of control over energy, water and material flows . Note that this is only used as on-site indicator. Off-site effects (on aquatic systems) of 
changing ET are not considered (see discussion). Soil cover (0-30 $\mathrm{cm}$ above ground level) is seen as an indicator of buffer capacity for raindrop impact and superficial erosion (Morgan 1995). Data on both of these indicators are available in geodatasets of LP DAAC, USA. Soil cover is also measurable on-field.

\section{Impact calculation}

The impact indicator scores (IS) are the summation of the relative impacts of the different land use activities of which a certain project or production process consists multiplied by the relative area of the activity $\left(\mathrm{A}_{\mathrm{i}}\right)$ (i.e. area of the activity under evaluation over the total area use of the project $\left(\mathrm{A}_{\mathrm{t}}\right)$ ). The relative impacts are the difference between the observed indicator value and the indicator value for the reference system (for the impact calculation of the land use change the reference system is the former land use, for impact of the land use occupation the reference system is the PNV), normalized by the indicator value of the potential natural vegetation (PNV) in the region. To express the product in percentage it is multiplied by 100 (Eq. 2).

$$
I S=\sum_{i}\left(\frac{A_{i}}{A_{t}} * \frac{\text { Value }_{\text {ref }}-\text { Value }_{\text {proj }, i} \mid}{\text { Value }_{P V N}}\right) * 100
$$

with $A_{i}$ is the area of the specific activity under evaluation, $A_{t}$ is the total area of the project site, Value $_{\text {proji,i }}$ is the value for the selected indicator for the project area of the specific activity under evaluation and Value ref is the value of the selected indicator for the reference system (i.e. former land use for land use change and PNV for land use occupation).

Table 1 gives an overview of the proposed indicators per mid-point impact aspect and the corresponding score calculation for land use change and land use occupation. Indicators and formula are chosen in such way that negative environmental impacts give a positive indicator score.

Based on these impact indicator calculations the impact indicator component for structural and functional land quality change due to land use occupation can be calculated.

$$
\begin{aligned}
I_{E S Q} & =\frac{\overline{I S_{S f}}+\overline{I S_{\alpha-B d}}+\overline{I S_{B p}}}{3} \\
I_{E F Q} & =\frac{\overline{I S_{S s}}+\overline{I S_{V s}}+\overline{I S_{W b}}}{3}
\end{aligned}
$$

with $I$ the impact indicator component and $\overline{I S_{\mathrm{x}}}$ the average indicator score for mid-point impact aspect $x$ ( $\mathrm{Sf}=$ Soil fertility; $\alpha-\mathrm{Bd}=\mathrm{On}$ site biodiversity; $\mathrm{Bp}=$ Biomass production; $\mathrm{Ss}=$ Soil structure; $\mathrm{Vs}=$ Vegetation structure and $\mathrm{Wb}=$ On site water balance) (Table 1). Eq. 3 and 4 will result in relative impacts on the land system structure and land system functioning expressed in percentages.

\section{LCA component}

The LCA component $(\mathrm{F})$ is necessary to present the impacts per FU. We propose to use the following F (Eq. 5) for both LUCh and LUOcc.

$$
F=\frac{(\text { time } * \text { area })}{F U}
$$


Where $F U$ is the functional unit of the project or production process and (time*area) is the area needed to produce a $F U$ for a specific period of time.

\section{Discussion}

This paper mainly aims to provide another approach to solve some general problems in land use impact assessment. Starting from a concept (MASD) which explains how, through ecosystem functions, an ecosystem works, lives and survives, we identified meaningful end-point impacts of human land use impacts. In the light of the MASD concept cause effect chains and possible mid-point indicators from literature were interpreted, leading to a balanced selection of a set of easily available or measurable mid-point indicators. Our proposal contains a dynamic use of our indicator set, where the user can argument to use only a minimum set of six indicators or to add specific indicators. The fact that for each mid-point impact, except soil fertility, data is available for at least one indicator, strengthens the dynamic and workable nature of this indicator set. The fact that averages of the mid point indicators are used downstream the calculation, overlap between the two selected indicators is not a problem Furthermore this indicator set gives a balanced look on basic impact themes: soil, water, vegetation and biodiversity.

Starting the approach from a general founding paradigm makes the proposed end-point impacts and indicator set applicable in different kinds of assessment tools, including LCA, as described in this paper (see LCA component).

The calculation of the land use change and occupation impact between the respective reference land use and the project land use relative to the local PNV results in a non site-specific impact (\%). As the impact is actually scaled against the maximum possible, the impact does not contain impacts of land use changes or occupations prior to the land use of interest of the LCA study.

Although this proposal contains improvements of earlier work there is still scope for improvement. (i) Currently off-site impacts are not considered. There is a clear need for addressing off-site effects on biodiversity and water balance (but see ). (ii) The aggregation of the mid-point impacts into the endpoint impacts is done using equal weighting. This is because of lack of information on the respective importance of the different variables in the ecosystem goal functions. 
6th International Conference on LCA in the Agri-Food Sector, Zurich, November 12-14, 2008

Table 1. Proposed indicators per mid-point impact aspect and impact score calculation for land use change and land use occupation

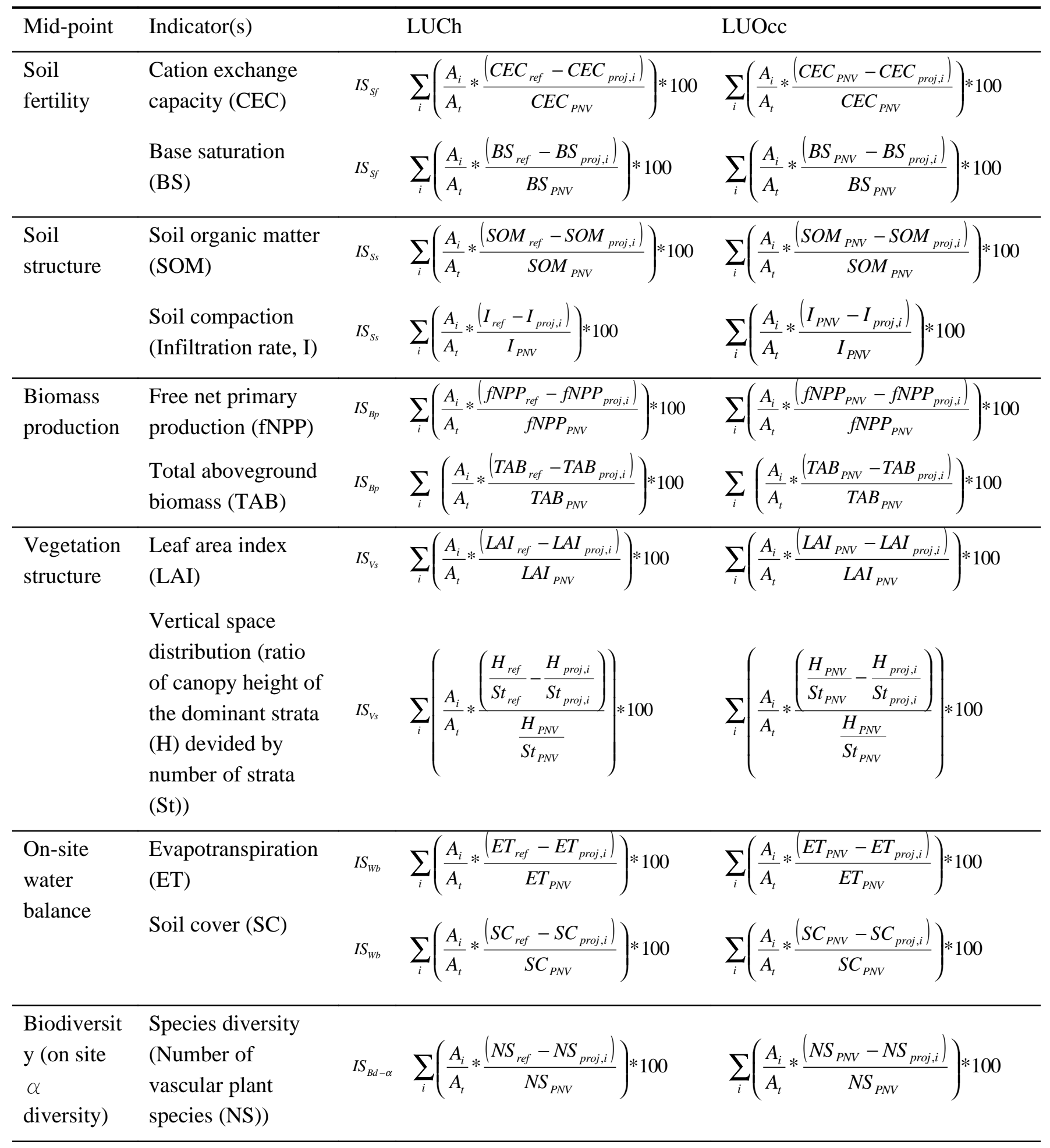


In addition to the link with the FU (LCA component), there is scope to include a temporal dimension in Eq. 1. This is particularly interesting in case of an impact fluctuating over time and consists of integrating the impact over time. This implies knowledge of how an impacting factor would intervene in the long term dynamics of an ecosystem. Therefore, calculation of this component will depend on the state of knowledge and on data availability.

\section{Acknowledgments}

This research is funded by the Flemish Interuniversity Council - University Development Cooperation (VLIR-UDC). The constructive comments provided by two anonymous reviewers are greatly appreciated.

\section{References}

Anzhi, W., L. Jinzhang, L. Jianmei, P. Tiefou, and J. Changjie. 2005. A semi-theoretical model of canopy rainfall interception for Pinus koraiensis nakai. Ecological Modelling 184:355-361.

Asano, Y. and T. Uchida. 2005. Quantifying the role of forest soil and bedrock in the acid neutralization of surface water in steep hill slopes. Environmental Pollution 133:467-480.

Asner, G.P. and K.B. Heidebrecht. 2005. Desertification alters regional ecosystem-climate interaction. Global Change Biology 11: 182-194.

Baelemans, A. and B. Muys. 1998. A critical evaluation of environmental assessment tools for sustainable forest management. In Proceedings of the international conference on Life Cycle Assessment in agriculture, agro-industry and forestry. Dec 3-4, 1998 Brussels, Belgium. Brussels, pp 65-75.

Baitz, M. 2007. We seldom think of what we have, but always think of what we miss. International Journal of Life Cycle Assessment 12:77-78.

Bendoricchio, G. and S.E. Jorgensen. 1997. Exergy as a goal function of ecosystem dynamics. Ecological Modelling 102:5-15.

Bronick, C.J. and R. Lal. 2005. Soil structure and management: a review. Geoderma 124: 3-22.

Cuartas, L.A., J. Tomasella, A.D. Nobre, M.G. Hodnett, M.J. Waterloo and J.C. Munera. 2007. Interception water-partitioning dynamics for a pristine rainforest in Central Amazonia: marked differences between normal and dry years. Agricultural and Forest Meteorology 145:69-83.

Dewulf, J., H. Van Langenhove, B. Muys, S. Bruers, B.R. Bakshi, G. Grubb, R.A. Gaggioli, D.M. Paulus, and E. Sciubba. 2008. Exergy: its potential and limitations in environmental science and technology. Environmental Science \& Technology 42:2221-2232.

Dungan, R.J., D. Whitehead, M. McGlone, R.B. Allen, and Duncan R.P. 2004. Simulated carbon uptake for a canopy of two broadleaved tree species with contrasting leaf habitats. Functional Ecology 18:34-42.

Esthetu, Z., R. Giester, and P. Hogberg. 2004. Historical land use pattern affects the chemistry of forest soils in the Ethiopian highlands. Geoderma 118:149-165.

Fath, B.D., B.C. Patten and J.S. Choi. 2001. Complementarity of ecological goal functions. Journal of Theoretical Biology 208:493-506.

Favre, F., D. Tessier, M. Abdelmoula, J.M. Genin, W.P. Gates, and P. Boivin. 2002. Iron reduction and changes in cation exchange capacity in intermittently waterlogged soils. European Journal of Soil Science 53:175183. 
Finnveden, G. and Östlund P. 1997. Exergies of natural resources in life-cycle assessment and other applications. Energy 22:923-931.

Garcia-Quijano, J. F., Peters, J., Cockx, L., van Wyk, G., Rosanov, A., Deckmyn, G., Ceulemans, R., Ward, S. M., Holden, N. M., Van Orshoven, J., and Muys, B. Carbon sequestration and environmental effects of afforestation with Pinus radiata D. Don in the Western Cape, South Africa. Climatic Change. 2007a.

Garcia-Quijano, J., J. Peters, L. Cockx, G. van Wyk, A. Rosanov, G. Deckmyn, R. Ceulemans, S. Ward, N. Holden, J. Van Orshoven, and B. Muys. 2007b. Carbon sequestration and environmental effects of afforestation with Pinus radiata D. Don in the Western Cape, South Africa. Climatic Change 83:323355.

Garcia-Quinjano, J.F. and A.P. Barros. 2005. Incorporating canopy physiology into a hydrological model: photosynthesis, dynamic respiration and stomatal sensitivity. Ecological Modelling 185:29-49.

Gomez, J.A., J.V. Giraldez, and E. Ferreres. 2001. Rainfall interception by olive trees in relation of leaf area. Agricultural Water Management 49:65-76.

Goyal, R.K. 2004. Sensitivity of evaporatranspiration to global warming: a case study of arid zone of Rajasthan (India). Agricultural Water Management 69:1-11.

Green, T.R., L.R. Ahuja, and J.G. Benjamin. 2003. Advances and challenges in predicting agricultural management effects on soil hydraulic properties. Geoderma 116:3-27.

Guinée, J., L. van Oers, A. de Koning and W. Tamis. 2006. In Life cycle approaches for conservation agriculture. Eds. J. Guinée, L. van Oers, A. de Koning and W. Tamis. Institute of Environmental Sciences - Leiden University, Leiden, the Netherlands, CML report 171, pp

Hagen-Thorn, A., I. Callesen, K. Ammolaitis, and B. Nihlgard. 2004. The impact of six European three species on the chemistry of mineral topsoil in forest plantations on former agricultural land. Forest Ecology and Management 195:373-384.

Heijungs, R., J. Guinée and G. Huppes. 1997. In Impact categories for natural resources and land use. Eds. R. Heijungs, J. Guinée and G. Huppes. Centre of Environmental Science (CML), Leiden, The Netherlands, CLM Report 138, pp

Heuvelmans, G., B. Muys, and J. Feyen. 2005. Extending the life cycle methodology to cover impacts of land use systems on the water balance. International Journal of Life Cycle Assessment 10:113-119.

Houghton, R.A. and J.L. Hackler. 1999. Emission of carbon from forestry and land use change in tropical Asia. Global Change Biology 5:481-492.

Johnson, C.E. 2002. Cation exchange properties of acid forest soils of the north-eastern U.S. European Journal of Soil Science 53:271-282.

Jonson-Maynard, J.L., R.C. Graham, L. Wu, and P.J. Shouse. 2002. Modification of soil structural and hydraulic properties after 50 years of imposed chaparral and pine vegetation. Geoderma 110:227-240.

Jorgensen, S.E. and H. Mejer. 1979. Holistic approach to ecological modelling. Ecological Modelling 7:169-189.

Kalnay, E. and M. Cai. 2003. Impact of urbanization and land-use change on climate. Nature 423:528-531.

Kettunen, R., S. Saarnia, P. Martikainen, and J. Silvola. 2005. Elevated $\mathrm{CO}_{2}$ concentration and nitrogen fertilization of $\mathrm{N}_{2} \mathrm{O}$ and $\mathrm{CH}_{4}$ fluxes and biomass production of Pheum pratense on farmed peat soil. Soil Biology and Biochemistry 37:739-750.

Komatsu, H., N. Tanaka, and T. Kume. 2007. Do coniferous forests evaporate more water than broad-leaved forests in Japan? Journal of Hydrology 336:361-375. 
Köllner, T. 2000. Species-pool effect potentials (SPEP) as a yardstick to evaluate land use impacts on biodiversity. Journal of Cleaner Production 8:293-311.

Lavy, P.E., M.G.R. Cannell, and A.D. Friend. 2004. Modelling the impact of future changes in climate, $\mathrm{CO}_{2}$ concentration and land use on natural ecosystems and the terrestrial carbon sink. Global Environmental Change 14:21-30.

Lindeijer, E. 2000. Biodiversity and life support impacts of land use in LCA. Journal of Cleaner Production 8:131-319.

Lindeijer E., R. Müller-Wenk and B. Steen. 2002. Impact assessment of resources and land use. In Life-cycle Impact Assessment: Striving towards Best Practice. Eds. H.A. Udo de Haes, G. Finnveden, M. Goedkoop, M. Hauschild, E.G. Hertwich, P. Hofstetter, O. Jolliet, W. Klöpffer, W. Krewitt, E.W. Lindeijer, R. Müller-Wenk, S.I. Olsen, D.W. Pennington, J. Potting, and B. Steen. Society of Environmental Toxicology and Chemistry, Pensacola, FL, pp 11-64.

Lindeijer, E. 2000. Review of land use impact methodologies. Journal of Cleaner Production 8:273-281.

Lyan, J. and N.M. Gross. 2005. Patterns of plant diversity and plant-environment relationship across three riparian corridors. Forest Ecology and Management 204:267-278.

Milà i Canals, L. 2007. Land use in LCA: a new subject area and call for papers. International Journal of Life Cycle Assessment 12:1.

Milà i Canals L. 2003. Contributions to LCA methodology for agricultural systems. Site-dependency and soil degradation impact assessment. Autonomous University of Barcelona.

Milà i Canals, L., C. Bauer, J. Depestele, A. Dubreuil, R. Freiermuth Knuchel, G. Gaillard, O. Michelsen, R. Müller-Wenk, and B. Rydgren. 2007. Key elements in a framework for land use impact assessment within LCA. International Journal of Life Cycle Assessment 12:5-15.

Milà i Canals, L., R. Clift, L. Basson, Y. Hansen, and M. Brandão. 2006. Expert workshop on land use impacts in life cycle assessment (LCA). International Journal of Life Cycle Assessment 11:363-368.

Milà i Canals, L., R. Müller-Wenk, C. Bauer, J. Depestele, A. Dubreuil, R. Freiermuth Knuchel, G. Gaillard, O. Michelsen, and B. Rydgren. 2007a. Key elements in a framework for land use impact assessment within LCA - Response to Helias Udo de Haes. International Journal of Life Cycle Assessment 12:2-4.

Milà i Canals, L., J. Romanya, and S.J. Cowell. 2007b. Method for assessing impacts on life support functions (LSF) related to the use of 'fertile land' in Life Cycle Assessment (LCA). Journal of Cleaner Production 15:1426-1440.

Miles, L., A. Oliver, and O. Phillips. 2004. The impact of global climate change on tropical forest biodiversity in Amazonia. Global Ecology and Biogeography 13:553-565.

Morgan R.P.C. 1995. Soil erosions and conservation. Longman group and J. Wiley \& Sons, England.

Mortimore, M., F.M.A. Haris, and B. Turner. 1999. Implications of land use change for the production of plant biomass in densely populated Sahelo-Sudanina shrub-grassland in north-east Nigeria. Global Ecology and Biogeography 8:243-256.

Munkholm, L.J., P. Schjonning, M.H. Jorgensen, and K. Thornp-Kristensen. 2005. Mitigation of subsoil recompaction by light traffic and on-land ploughing: II. Root and yield response. Soil and Tillage Research 80:159-170.

Obrist, D.V.P.S.J., M.H. Young, J.S. Coleman, D.E. Schorrau, and J.A. Anone. 2003. Quantifying the effects of phenology on ecosystem evapotranspiration in planted grassland mesocosms using EcoCELL technology. Agricultural and Forest Meteorology 112:65-84. 
Onaindia, M., I. Dominguez, I. Albizu, C. Gabisu, and I. Amezaga. 2004. Vegetation diversity and vertical structure as indicators of forest disturbance. Forest Ecology and Management 195:341-354.

Pañuelas, J., I. Filella, X. Zhang, L. Llorens, R. Ogaya, F. Lloret, P. Comas, M. Estiarte, and J. Terrada. 2003. Complex spatiotemporal phenological shifts as a response to rainfall changes. New Phytologist 161:837846.

Peters, J., J. Garcia-Quijano, T. Content, G. Van Wyk, N.M. Holden, S.M. Ward, and B. Muys. 2003. A new land use impact assessment method for LCA: theoretical fundaments and field validation. In Life Cycle Assessment in the Agri-food sector. Proceedings from the $4^{\text {th }}$ International Conference. Bygholm, Denmark. 143-156.

Rascher, U., E.G. Bobich, G.H. Lin, A. Walter, T. Morris, M. Naumann, C.J. Nichal, D. Pierce, K. Bil, K. Kudeyarov, and J.A. Berey. 2004. Functional diversity of photosynthesis during drought in a model tropical rainforest - the contributions of leaf area, photosynthetic electron transport and stomatal conductance to reduction in net ecosystem carbon exchange. Plant, Cell and Environment 27:1239-1256.

Rutigliano, F.A., R. D'ascoli and A.V. De Santo. 2004. Soil microbial metabolism and nutrient status in a Mediterranean area as affected by plant cover. Soil Biology \& Biochemistry 36:1719-1729.

Schellekens, J., F.N. Scatena, L.A. Bruijnzeel, and A.J. Wickel. 1999. Modelling rainfall interception by a lowland tropical rain forest in north-eastern Puerto Rico. Journal of Hydrology 225:168-184.

Scheller, R.M. and D.J. Mladenoff. 2005. A spatial interactive simulation of climate change, harvesting, wind and tree species migration and projected changes to forest composition and biomass in northern Wisconsin, USA. Global Change Biology 11:307-321.

Schneider, E.D. and J.J. Kay. 1994. Life and manifestation of the second law of thermodynamics. Mathematical and computer modelling 19:25-48.

Schneider E.D. and J.J. Kay. 1995. Order from disorder: the thermodynamics of complexity in biology. In Wathi s life: the next fifty years. Reflections on the future of biology. Eds. M.P. Murphy and L.A.J. O'Neill. Cambridge University Press, Cambridge, pp 161-172.

Son, Y., J.H. Park, M.Y. Yi, H.O. Jin, R.H. Kim, and J.O. Hwang. 2004. Biomass, production and nutrient distribution of a natural oak forest in Central Korea. Ecological Research 19:21-28.

Stephens, S.L. and S.J. Gill. 2005. Forest structure and mortality in an old growth Jeffrey pine mixed conifer forest in north-western Mexico. Forest Ecology and Management 205:15-28.

Udo de Haes, H.A. 2006. How to approach land use in LCIA or, how to avoid the Cinderella effect? International Journal of Life cycle assessment 11:219-221.

Van Dijk, A.I.J.M. and L.A. Bruijnzeel. 2001. Modelling rainfall interception by vegetation of variable density using an adapted analytical model. Part 1: Model description. Journal of Hydrology 247:230-238.

Wehrli, A., A. Zingg, H. Bugmann, and A. Huth. 2005. Using a forest patch madel to predict the dynamics of stand structure in Swiss mountains forests. Forest Ecology and Management 205:149-167.

Will, R.E., N.V. Narahari, B.D. Shiver, and R.O. Teskey. 2005. Effects of planting density on canopy dynamics and stem growth for intensively managed loblolly pine stand. Forest Ecology and Management 205:2941. 